\title{
The Barriers towards the Adoption of E-Wallet Payment System
}

\author{
${ }^{1}$ Nur Izzati Mohamad Anuar, ${ }^{1}$ Nik Malini Nik Mahdi, ${ }^{2}$ Nik Alif Amri Nik Hashim, ${ }^{1}$ Siti Rohana Mohamad, \\ ${ }^{1}$ Siti Afiqah Zainuddin, ${ }^{1}$ Nur Farahiah Azmi, \& ${ }^{1}$ Wan Farha Wan Zulkiffli \\ ${ }^{1}$ Faculty of Entrepreneurship and Business, Universiti Malaysia Kelantan
}

${ }^{2}$ Faculty of Hospitality, Tourism and Wellness, Universiti Malaysia Kelantan

\begin{abstract}
Many countries including Malaysia are aiming for cashless society, in which represent the transition of business transaction from cash to electronic-based transactions. Hence, the escalating trend of using electronic payment system can be observed especially during the COVID-19 crisis where consumers are transitioning to electronic commerce (ecommerce) as well as mobile commerce (m-commerce) business, however there are consumers who are not keen on ewallet usage. Thus, this research aims to investigate the barriers towards the adoption of E-Wallet payment system. Based on Innovation Resistance Theory (IRT), the barriers refer to the factors of value barrier (VB), usage barrier (UB), risk barrier $(\mathrm{RB})$ and perceived cost barrier $(\mathrm{PCB})$. The results of the research were obtained from 248 respondents of fourth year students in the Faculty of Entrepreneurship and Business, University Malaysia Kelantan with the help of Krejcie and Morgan table sampling method and through the use of questionnaire. Besides, Statistical Package of Social Sciences (SPSS) method and Spearman's correlation analysis were also used to analyze the data from the questionnaire. It was found that value barrier, usage barrier, risk barrier as well as perceived cost barrier have a significant relationship with the adoption of E-wallet payment system. As the results highlighted the barricades that cease an individual from using e-wallet despite of its benefits, the policy maker can ponder the result to accelerate the adoption of e-wallet to a more desirable level in the nation.
\end{abstract}

Keywords: Barrier, Adoption, E-Wallet, Value Barrier, Usage Barrier, Risk Barrier, Perceived Cost Barrier

\section{INTRODUCTION}

The emerging trend of e-commerce and m-commerce in the recent years entails the improvement of its processes and systems to ensure effective and efficient transactions [19]. This includes the electronic payment processes and systems, in which consumers and traders are advised to use e-wallet; a convenient, user-friendly and secure payment system [30]. It is an application that allows an individual to perform any ecommerce transactions by storing their debit or credit card information [30; 13]. Just like a physical wallet with sufficient cash, e-wallet needs digital funds to function and complete the transactions. It also allows consumers to manage their purchases loyalty, membership, and banking information centrally instead of having several cards in their physical wallet $[30 ; 10 ; 13]$. Each country has its own preferences when it comes to e-wallets and according to Karim et al. (2020), AEON Wallet, Boost, BigPay, GrabPay, WeChat pay and Touch ' $\mathrm{n}$ Go are among the most popular e-wallets in Malaysia. As cashless society could save up to $1 \%$ of a country's economy due to lower retail payment cost as compared to the reliance on cash-based transactions [20], the initiatives to encourage the adoption of e-wallet in Malaysia has been progressive. A one-off digital incentive was given to eligible Malaysians under e-Tunai Rakyat with RM450 million budget allocation. In order to speed up the adoption of e-wallets among both users and merchants, three official ewallet partners including Touch 'n Go, Boost and GrabPay, were selected based on four measures: a significant number of active users, a great level of capability, a wide network of merchants as well as a significant volume of investment in their own services in Malaysia [29]. Nonetheless, Covid-19 crisis has shaped the role of e-wallet from just a convenience mean for consumers and even merchants, to a necessary tool to embrace the "new normal". Recently, an allocation of RM750 million under Malaysia's Economic Recovery Plan called PENJANA was announced to drive the adoption of ewallets in Malaysia during the COVID-19 pandemic. The perceived risk of COVID-19 crisis significantly influences the intention of Malaysian consumers to use e-wallet [18]. Despite of the threat of COVID-19 crisis, the phenomena of ewallet in Malaysia is growing at slower pace than its regional peers $[2 ; 12]$. It is observed that Malaysian consumers are still transitioning towards an emerging market, the processes as well as systems of e-commerce is still developing and they are still relying on cash-based transactions [19]. In 2017, only $68 \%$ of respondents were using electronic payment and moving away from cash and $32 \%$ of respondents were not familiar with the system [6]. On the other perspective, Malaysia market is well-served by online banking, debit card and credit cards that draw back the importance of e-wallet at the eyes of Malaysian consumers [20; 32]. In contrast, China shows the great level of e-wallet adoption since the market is under-served by card network [20]. Thus, there are some Malaysians who is still lagging in embracing e-wallet despite its robust development before and during the COVID-19 crisis. Hence, the issue of refusal to adopt e-wallet by Malaysian consumers could be due to the merchants, the 
consumers and even the developers, which need to be investigated further. Therefore, there were four research objectives which include 1) To examine the relationship between usage barrier and adoption of E-wallet payment; 2) To examine the relationship between value barrier and adoption of E-wallet payment system; 3) To examine the relationship between risk barrier and adoption of E-wallet payment system; and 4) To examine relationship between perceived cost barrier and adoption of E-wallet payment system.

\section{LITERATURE REVIEW}

\subsection{Innovation Resistance Theory (IRT)}

In basis, IRT was proposed by Ram (1987) [22] and later modified by Ram and Sheth (1989) [23]. It focuses on consumers' response to any product in terms of barriers such as usage, risk, value, tradition and image, which provide scholars with a theoretical basis to explain the resistance towards innovations that never cease progressing and entering the market [23]. There is a large number of studies that examined the resistance towards innovations such as ecommerce and $\mathrm{m}$-commerce however, less attention has been given to examine the resistance towards e-wallet payment system (Aransyah et al., 2020).

\subsection{Adoption of E-wallet Payment}

Straub (2009) proposed that an individual has a choice whether to refuse or accept an innovation. Straub (2009) also proposed that the innovation is prone to fail if the resistance cannot be overcome which consequently slows down the adoption process. Thus, there is a need to answer why some individuals opt to refuse e-wallet payment system and why certain individuals choose to adopt it? [28]. What are the barriers of adopting e-wallet payment system? [28].

\subsection{Value Barrier}

As a consumer refuse to change unless an innovation offers greater value from the substitute, value barrier is the resistance towards an innovation due to the value of innovation from the perspective of consumers [23]. It also refers to the degree of benefits versus the cost of using the technology [8; 15]. Antico and Kleijnen (2009) proposed that value barrier is one of the functional barriers besides of usage and risk barrier. Empirically, they supported the relationship between value barrier and the adoption of technological innovation. This has been supported by Cheng et al. (2018) who found that usage barrier is significantly and positively influence the resistance of consumers to adopt e-wallet payment system. Recently, Aransyah et al. (2020) also supported that value barrier positively influence the resistance of consumers to adopt e-wallet payment system. It is suggested that consumers are more likely to refuse when they perceive the substitutes of e-wallet have higher value to serve them [3].

H1: There is a significant relationship between value barrier and the adoption of e-wallet payment system.

\subsection{Usage Barrier}

As an innovation requires changes from a consumer since new skills need to be learned and existing habits need to be modified for using a new product or service before it can be fully accepted, usage barrier is the resistance towards an innovation due to the inconsistency with current routine, exercise and plan [23]. Thus, it also refers to the degree of difficulty for an individual to understand and use the technology [24; 14]. According to Moorthy et al. (2017) [16], usage barrier significantly affects the adoption of innovation. This has been supported by Cheng et al. (2018) who found that usage barrier is significantly and positively influence the resistance of consumers towards adopting e-wallet payment system.

$\mathrm{H} 2$ : There is a significant relationship between usage barrier and the adoption of e-wallet payment system.

\subsection{Risk Barrier}

As an innovation comes with potential side effects, risk barrier is the resistance towards an innovation due to the uncertainty which result from adopting a new product or service $[23 ; 11]$. Hence, consumers who are aware with the risk may oppose the technology and they will wait until they get more knowledge about the modification [23]. It was found that risk barrier is significantly associated with the adoption of e-wallet payment system [5].

H3: There is significant relationship between risk barrier and the adoption of e-wallet payment system.

\subsection{Perceived Cost Barrier}

Lu et al. (2011) proposed that additional monetary expenses are involved when a consumer is using a technology, in which measured as consumer's perceptions of cost. Thus, perceived cost barrier is the resistance towards an innovation due the degree of consumer's expectations on how costly it would be to adopt an invention. Although Chan et al. (2015) found that perceived cost barrier is not associated with the adoption of ewallet payment system, Sahut (2008) stressed out that the cost of e-wallet significantly affect its adoption rate. It is crucial to ensure that the advantages of e-wallet can compensate for the share of cost incurred [25].

H4: There is a significant relationship between perceived cost barrier and the adoption of e-wallet payment system. 


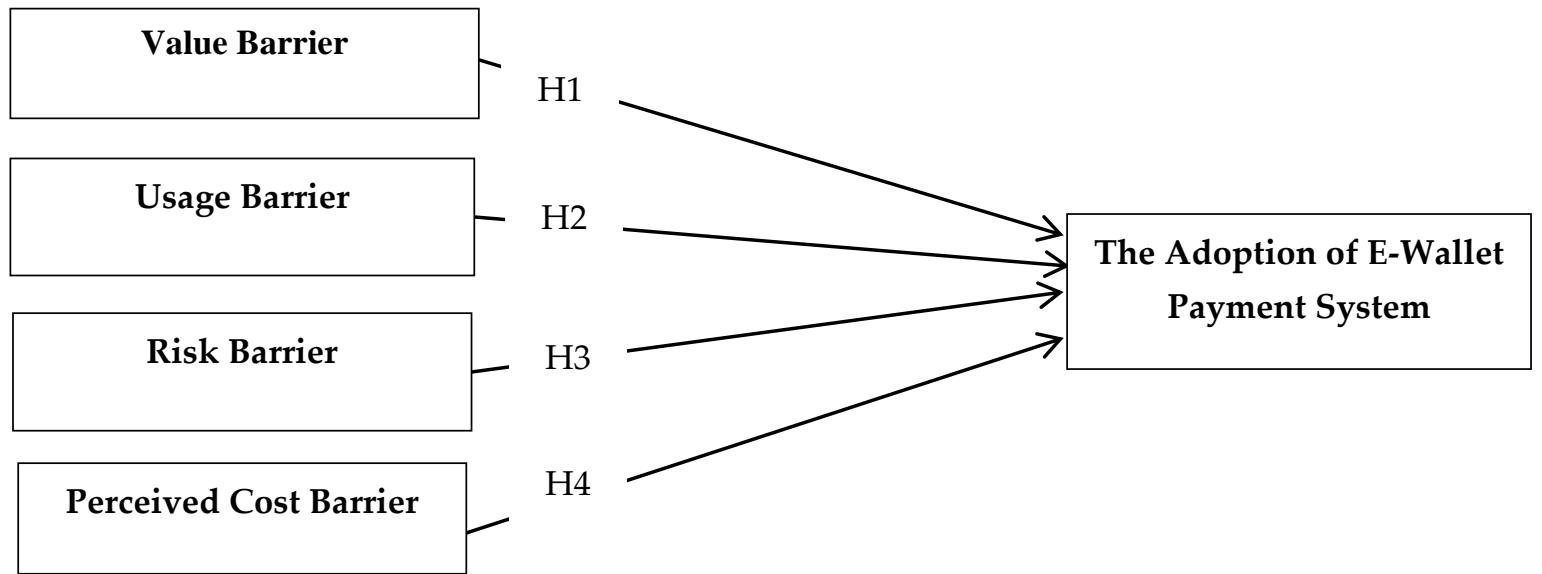

Figure 1: Research Framework

\section{CONCEPTUAL FRAMEWORK}

Based on Innovation Resistance Theory (IRT), the conceptual framework was developed to answer the research objectives. Based on Figure 1.0, the independent variables are value barrier, usage barrier, risk barrier as well as perceived cost barrier and the dependent variable is the adoption of e-wallet payment system.

\section{METHODOLOGY}

This research adopted a quantitative approach. Based on Krejcie and Morgan (1970), the sample size was set at 248 considering the total number of fourth year students in the Faculty of Entrepreneurship of Business is 686. They are from different major of studies, yet they are under entrepreneurial studies which is very close to the research topic; online payment system. A non-probability sampling method which is convenience sampling was used to collect the data through the questionnaire which includes three sections. Section A has demographic questions. On the other hand, section B and section $\mathrm{C}$ include series of questions related to independent variables and dependent variables with a 5 point of Likert Scale. A pilot test was conducted prior to data collection for reliability [27]. Since the value of Cronbach's alpha of all variables are above 0.7 , this indicates the reliability of questionnaire [27].

\section{FINDINGS}

Table 4.1 shows the frequency summary of demographic profile which includes the involved respondents' gender, age, race, course as well as their e-wallet usage and frequency. Based on the collected and analyzed data of students in the Faculty of Entrepreneurship and Business, it was found that $69.3 \%$ of respondents are e-wallet users and $30.2 \%$ of respondents are not adopting any e-wallet to perform online transaction. Even though there are more than $50 \%$ of respondents who adopt e-wallet payment system, only $4.4 \%$ of respondents are using e-wallet in a daily basis, $20.6 \%$ of respondents are using e-wallet in a weekly basis and $29.8 \%$ of respondents are using this tool in a monthly basis. There was a

slightly difference between the percentage of non-users of ewallet $(30.2 \%)$ and the percentage of users who never use ewallet $(27.4 \%)$. This can be due to the users who install the ewallet applications, so they consider themselves as e-wallet users but, they never actually use it.

Table 1: Respondents Profile

\begin{tabular}{|l|l|l|}
\hline GENDER & FREQUENCY & PERCENT (\%) \\
\hline Male & 154 & 62.1 \\
\hline Female & 94 & 37.9 \\
\hline Total & 248 & 100.0 \\
\hline AGE & FREQUENCY & PERCENT (\%) \\
\hline 18-21 years & 21 & 8.5 \\
\hline $22-25$ years & 210 & 84.7 \\
\hline 26 and above & 17 & 6.9 \\
\hline Total & 248 & 100.0 \\
\hline RACE & FREQUENCY & PERCENT (\%) \\
\hline Malays & 123 & 49.6 \\
\hline Chinese & 74 & 29.8 \\
\hline Indian & 45 & 45 \\
\hline Batak & 1 & 0.4 \\
\hline Kenyah & 1 & 0.4 \\
\hline Rungus & 1 & 0.4 \\
\hline Thailand & 1 & 0.4 \\
\hline Total & 248 & 100.0 \\
\hline COURSE & FREQUENCY & PERCENT (\%) \\
\hline Commerce & 105 & 42.3 \\
\hline Islamic Banking & 34 & 13.7 \\
\hline Retailing & 46 & 19.4 \\
\hline Logistics & 48 & 18.5 \\
\hline Entrepreneurship & 15 & 6.0 \\
\hline Total & 248 & 100.0 \\
\hline
\end{tabular}




\begin{tabular}{|l|l|l|}
\hline USER & FREQUENCY & PERCENT (\%) \\
\hline Yes & 173 & 69.8 \\
\hline No & 75 & 30.2 \\
\hline Total & 248 & 100.0 \\
\hline FREQUENCY & FREQUENCY & PERCENT (\%) \\
\hline Never & 68 & 27.4 \\
\hline Daily & 11 & 4.4 \\
\hline Weekly & 51 & 20.6 \\
\hline Monthly & 74 & 29.8 \\
\hline Year & 44 & 17.7 \\
\hline Total & 248 & 100.0 \\
\hline
\end{tabular}

The hypotheses of this research were analyzed using Spearman correlation as the data was not normally distributed [17]. Table 4.2 shows the significant relationships between respective independent variables (IVs) and dependent variable (DV) as the p-value less than 0.05 (typically $\leq 0.05$ ) is statistically significant. Therefore, all hypotheses are supported. Referring to the rule of thumb for interpreting Spearman's correlation coefficient [17], the value of correlation coefficient for the first hypothesis is 0.313 which indicates a negative relationship between value barrier and the adoption of e-wallet payment system. This exemplifies that when value barrier increases, the adoption of e-wallet payment system decreases. Similarly, the value of correlation coefficient for the second hypothesis is 0.341 which indicates a negative relationship between usage barrier and the adoption of e-wallet payment system. This also exemplifies that when usage barrier increases, the adoption of e-wallet payment system decreases. On the other hand, even though the third and fourth hypotheses are significant, the value of correlation coefficient of the first is only 0.240 and the latter is only 0.190 which show negligible correlation between IV and DV.

Table 2: Summary of Correlation Analysis

\begin{tabular}{|c|c|c|c|c|}
\hline \multicolumn{2}{|c|}{ Hypothesis } & \multirow{2}{*}{$\begin{array}{c}\text { Sig (2-tailed) } \\
0.000\end{array}$} & \multirow{2}{*}{$\begin{array}{c}\begin{array}{c}\text { Spearman } \\
\text { Correlation }\end{array} \\
0.313\end{array}$} & \multirow{2}{*}{$\begin{array}{l}\begin{array}{l}\text { Alternative } \\
\text { Hypothesis }\end{array} \\
\text { Supported }\end{array}$} \\
\hline H1 1 & $\begin{array}{l}\text { There is a significant relationship between value barrier and } \\
\text { the adoption of e-wallet payment system. }\end{array}$ & & & \\
\hline $\mathrm{H1}_{2}$ & $\begin{array}{l}\text { There is a significant relationship between usage barrier and } \\
\text { the adoption of e-wallet payment system. }\end{array}$ & 0.000 & 0.341 & Supported \\
\hline $\mathrm{H1}_{3}$ & $\begin{array}{l}\text { There is a significant relationship between risk barrier and } \\
\text { the adoption of e-wallet payment system. }\end{array}$ & 0.000 & 0.240 & Supported \\
\hline $\mathrm{H1}_{4}$ & $\begin{array}{l}\text { There is a significant relationship between perceived cost } \\
\text { barrier and the adoption of e-wallet payment system. }\end{array}$ & 0.003 & 0.190 & Supported \\
\hline
\end{tabular}

Source: SPSS output

\section{DISCUSSIONS AND RECOMMENDATIONS}

This research found that when e-commerce users deemed ewallet as inconvenience process of switching from cash to electronic payment, they are most likely to resist from adopting e-wallet payment system. This validates the hypothesis and explains the negative correlation between usage barrier and the adoption of e-wallet payment system. The provider should be able to provide the ease of use in terms of convenience as the limitation to experience it consequently limits the use of e-wallet payment system by the user [33].

Besides, it was found that when e-commerce users find that ewallet is hard to use and causing them confusion to perform the transaction, they tend to refuse its adoption. This validates the hypothesis and explains the negative correlation between usage barrier and the adoption of e-wallet payment system. In some countries, lack of literacy is seen as the major barrier for its citizen to adopt m-commerce activities and customer care points are needed to mitigate the problem [21]. In fact, lack of information literacy also can lead to underutilization of information and communication technology [26].

On the other hand, the third hypothesis was supported with a negligible correlation. Even though previous studies suggested that risk barrier as one of the major factors that influence the adoption of technology, this study found that the fears of personal error, privacy violation, security violation and not having sufficient battery may lead to the adoption of e-wallet payment system and even the refusal to adopt this technology [4; 9]. Dotzauer and Hais (2017) [7] also found the significant relationship between risk barrier and the adoption of technology but they also highlighted that certain consumer characteristics influence the perception of barriers and consequently influence the adoption of innovation. Beforehand, Rahman (2013) proclaimed that the respondents are confident to conduct monetary transactions via online despite the technological risk that may occur.

Similarly, the fourth hypothesis was supported with a negligible correlation. This is consistent with Rahman (2013) 
who proclaimed that it is only a minor relationship between perceived cost barrier and the adoption of technology in developing country like Bangladesh. Based on United Nations (2020) [31], Malaysia is also a developing country. Besides that, Zhao and Kurnia (2014) found that the respondents may adopt the technology even though there is extra cost for using the system especially at the early stage of offering technology service.

\section{CONCLUSION}

In a nutshell, the barriers of value, usage, risk as well as perceived cost that consumers are facing, should be reduced in order to achieve the greater level of adoption of e-wallet payment system in Malaysia. This is crucial to be considered considering that great initiatives have been taken to speed up the adoption of e-wallets as well as to encourage safe and contact-free payment during COVID-19 pandemic. However, the researchers were challenged with limitations such as time constraint. Hence. the findings of the research were only representing fourth year students in the Faculty of Business and Entrepreneurship in one of public higher education institutions in Malaysia. Thus, it is recommended that students from first year until third year are included to provide more conclusive results. Besides, as this research only focused on value barrier, usage barrier, risk barrier as well as perceived cost barrier, future research can be extended to include other variables such as image barrier, tradition barrier as well as perceived novelty barrier. Other relevant variable such as consumer characteristics also can be included into the conceptual framework. This will provide beneficial insights on the other barriers that can influence the adoption of ewallet payment system as well as possible factors that can affect the relationship. Last but not least, future research can be extended to qualitative approach in order to explore attitudes, behaviour and experience based qualitative methods such as in-depth interview, focus group or even participant observation.

\section{ACKNOWLEDGEMENT}

A special thanks to the authors from Faculty of Entrepreneurship and Business and Faculty of Hospitality, Tourism and Wellness, Universiti Malaysia Kelantan for their time and cooperation to publish this article

\section{REFERENCES}

[1] Aji, H. M., Berakon, I., \& Husin, M. M. (2020). COVID-19 and e-wallet usage intention: A multigroup analysis between Indonesia and Malaysia. Cogent Business \& Management, 7(1), 1804181.

[2] Andrew, J. V., \& Tan, K. E. (2019). A model of factors influencing consumers' intention to use e-wallet system in Malaysia: A systematic review. Malaysian Journal of Business and Economics (MJBE), 53-53.

[3] Antioco, M., \& Kleijnen, M. (2010). Consumer adoption of technological innovations. European

\section{Journal of Marketing.}

[4] Aziz, R. C., Hashim, N. A. A. N., Omar, R. N. R., Yusoff, A. M., Muhammad, N. H., Simpong, D. B., Abdullah, T., Zainuddin, S. A., \& Safri, F. H. M. (2019). Teaching and Learning in Higher Education: ELearning as a Tool. International Journal of Innovative Technology and Exploring Engineering (IJITEE), 9(1), 458-463.

[5] Cheng, S. W., Cheong, M., Lee, J. L., Lim, J. T., \& Mok, W. K. (2018). Curbs on modern technology: barriers of resistance towards e-wallet in Malaysia (Doctoral dissertation, UTAR).

[6] Dass, F. (2017). Malaysians prefer using electronic payments over cash: Visa. Retrieved from https://www.nst.com.my/business/2017/04/229434/mal aysians-prefer-using-electronic-payments-over-cashvisa

[7] Dotzauer, K., \& Haiss, F. (2017). Barriers towards the adoption of mobile payment services. (Master's thesis, Karlstad University, Sweden).

[8] Dunphy, S. \& Herbig, P. A. (1995), Acceptance of innovations: the customer is the key!. Journal of High Technology Management Research, 6(2), pp. 193-209.

[9] Ghoreishii, B., Khaleghi Esfahani, M., Alizadeh Lushabi, N., Amini, O., Aghamolaie, I., Hashim, N. A. A. N., \& Alizadeh, S. M. S. (2020). Assessment of Geotechnical Properties and Determination of Shear Strength Parameters. Geotechnical and Geological Engineering.

[10] Hashim, N. A. A. N., Ramlee, S. I. F., Yusoff, A. M., , Nawi, N. M. N., Awang, Z., Zainuddin, S. A., , Abdullah, T., Ahmad, G., Rahim, M. A., \& Fatt, B. S. (2019). Internet Shopping: How the Consumer Purchase Behaviour is Impacted by Risk Perception. TEST Engineering \& Management, 59(6S), 1014-1021.

[11] Hashim, N. A. A. N., Safri, F. H. M., Yusoff, A. M., Omar, R. N. R., Velayuthan, S. K., Hashim, H., Aziz, R. C., Awang, Z., Ahmad, G., \& Fatt, B. S. (2019). Disintermediation Threat: How and What Strategies are Used by Traditional Travel Agency to Survive?. TEST Engineering \& Management, 59(6S), 1022-1031.

[12] Hashim, N.A.A.N., Bakar, N.A., Zain, E.N.M., Yusoff, N.D.M., \& Muhammad, N.H. (2020). Travel Mobile Applications Technology: Examining the Reliability and Validity of Instruments. International Journal of Advanced Science and Technology, 29(9S), 7774-7777.

[13] Karim, M. W., Haque, A., Ulfy, M. A., Hossain, M. A., \& Anis, M. Z. (2020). Factors influencing the use of Ewallet as a payment method among Malaysian young adults. Journal of International Business and Management, 3(2), 01-12.

[14] Laukkanen, T., \& Cruz, P. (2008, July). Barriers to mobile banking adoption-A cross-national study. In International Conference on E-business, 2, 300-306.

[15] Laukkanen, T., Sinkkonen, S., Kivijärvi, M., \& Laukkanen, P. (2007). Innovation resistance among mature consumers. Journal of Consumer Marketing.

[16] Moorthy, K., Suet Ling, C., Weng Fatt, Y., Mun Yee, C., Ket Yin, E. C., Sin Yee, K., \& Kok Wei, L. (2017). Barriers of mobile commerce adoption intention: 
International Journal of Engineering Research and Technology. ISSN 0974-3154, Volume 13, Number 11 (2020), pp. $3772-3777$

(C) International Research Publication House. https://dx.doi.org/10.37624/IJERT/13.11.2020.3772-3777

perceptions of generation $\mathrm{X}$ in Malaysia. Journal of Theoretical and Applied Electronic Commerce Research, 12(2), 37-53.

[17] Mukaka, M. M. (2012). Statistics corner: a guide to appropriate use of correlation coefficient in medical research. Malawi Medical Journal, 24(3), 69-71.

[18] Nik Hashim, N.A.A., Yusoff,A.M., Awang,Z., Aziz,R.C., Ramlee, S.I.F., Bakar,N. A., Noor, M.A.M. \& Fatt, B.S. (2019). The Effect of Domestic Tourist Perceived Risk on Revisit Intention in Malaysia. International Journal of Innovative Technology and Exploring Engineering (IJITEE), 8(10),4591-4596.

[19] Nizam, F., Hwang, H. J., \& Valaei, N. (2018). Measuring the effectiveness of e-wallet in Malaysia. In 3rd IEEE/ACIS International Conference on Big Data, Cloud Computing, and Data Science Engineering (pp. 59-69). Springer, Cham.

[20] Oh, A. (2018). The e-wallet infinity war in Malaysia Everything you need to know about e-wallet starts here... $\quad$ Retrieved from https://www.ecinsider.my/2018/12/malaysia-ewalletbattle-landscape-analysis.html

[21] Rahman, M. M. (2013). Barriers to M-commerce adoption in developing countries-a qualitative study among the stakeholders of Bangladesh. The International Technology Management Review, 3(2),80-91.

[22] Ram, S. (1987). A model of innovation resistance. ACR North American Advances.

[23] Ram, S., \& Sheth, J. N. (1989). Consumer resistance to innovations: the marketing problem and its solutions. Journal of Consumer Marketing.

[24] Rogers, E., 2003. Diffusion of Innovations, Free Press. New York, 5th edition.

[25] Sahut, J. M. (2008). The adoption and diffusion of electronic wallets. International Journal of Social, Behavioral, Educational, Economic, Business and IndustrialEngineering, 2(5), 525-528.

[26] Salleh, M. I., Halim, A. F., Yaacob, R. A. R., \& Yusoff, Z. (2011). Measuring the effect of information literacy on the undergraduates' academic performance in higher education. In International Conference on Social Science and Humanity, 5(2).

[27] Sekaran, U., \& Bougie, R. (2016). Research methods for business: A skill building approach. John Wiley \& Sons.

[28] Straub, E. T. (2009). Understanding technology adoption: Theory and future directions for informal learning. Review of Educational Research, 79(2), 625649.

[29] Tan, J. (2020). RM30 e-Tunai Rakyat E-Wallet Initiative: What You Need to Know. Retrieved from https://ringgitplus.com/en/blog/e-wallet/rm30-e-tunairakyat-e-wallet-initiative-what-you-need-to-know.html

[30] Uddin, M. S., \& Akhi, A. Y. (2014). E-wallet system for Bangladesh an electronic payment system. International Journal of Modeling and Optimization, 4(3), 216.

[31] United Nations (2020). World economic situation and prospects.

Retrieved from

https://www.un.org/development/desa/dpad/wpcontent/uploads/sites/45/WESP2020_Annex.pdf

[32] Zain, E.N.M., Ghazali, P.L., Wan Daud, W.M.N. (2020). Determinants of non-performing loans: Evidence from conventional banks in Malaysia, Humanities and Social Sciences Reviews, 8(2), 423430.

[33] Zhao, Y., \& Kurnia, S. (2014). Exploring Mobile Payment Adoption in China. In PACIS (p. 232). 